\title{
Psychosocial Impact of Living with a Stuttering Disorder: Knowing Is Not Enough
}

\author{
Janet Beilby, Ph.D. ${ }^{1}$
}

\section{ABSTRACT}

Stuttering requires a multidimensional perspective given that, in recent years, researchers have shown the impact of the disorder to reach far beyond the surface components with demonstrated psychosocial and anxiety effects for the individual living with a stutter. This article explores the impact a stuttering disorder has on the individual (child, adolescent, and adult) and on their family members (siblings, parents, and partners). These experiences include behavioral and social difficulties, self-awareness, reactions to stuttering, communication difficulties in daily situations, and overall quality of life. The influence of stuttering on the most intimate relationships of the person who stutters is presented. An overview of stuttering across the life span is discussed in terms of stuttering in children and adolescents, and the significant levels of adverse impact as a result of living with a stutter are described. In addition, the impact that the stuttering disorder has on the parents and siblings of children who stutter is also detailed through significant findings pertaining to lack of attachment and trust between the young people and their parents. The responsibilities and demands on parents and siblings in the family context are highlighted. Focus is also placed on the experience of living with a person who stutters from the perspective of their life partner. Perceived quality of life is explored with unexpected differences recounted between the quality of life experienced by the adult who stutters and their partner's perceptions of this disorder. Finally, the potential for a novel Acceptance and Commitment Therapy for individuals who stutter is presented.

KEYWORDS: Stuttering, psychosocial, parents, siblings, partners, quality of life, ACT

${ }^{1}$ School of Psychology and Speech Pathology, Curtin University, Perth, Western Australia, Australia.

Address for correspondence: Janet Beilby, Ph.D., School of Psychology and Speech Pathology, Curtin University, GPO Box U 1987, Perth, 6845 Western Australia, Australia (e-mail: J.Beilby@curtin.edu.au).

Brain, Temperament, and Behavior: New Approaches to Understanding Fluency Disorders; Guest Editor, Vivian Sisskin, M.S., F-ASHA
Semin Speech Lang 2014;35:132-143. Copyright (C) 2014 by Thieme Medical Publishers, Inc., 333 Seventh Avenue, New York, NY 10001, USA. Tel: +1(212) 584-4662. DOI: http://dx.doi.org/10.1055/s-0034-1371756.

ISSN 0734-0478. 
Learning Outcomes: As a result of this activity, the reader will be able to (1) describe the reactions and speaking experiences of children and adolescents who stutter compared with those who do not stutter; (2) recall that the impact of the disorder of stuttering is not related to the degree of severity; (3) discuss clinical outcomes including more realistic goals such as some stuttered speech and acceptance of "normal" reactions to speaking include reasonable levels of concern; (4) express how the quality of the sibling relationship differs when there is a sibling in the family who stutters; (5) identify how the parent-child relationship is impacted upon by the consequences of living with the stutter over time; (6) recall the themes that partners of adults who stutter share with their loved one while appreciating different quality of life perspectives; (7) define the potential for Acceptance and Commitment Therapy for individuals who stutter.

\section{STUTTERING AS A}

\section{MULTIDIMENSIONAL DISORDER}

Presumably, everyone who reads this special edition of Seminars in Speech and Language finds stuttering to be an intriguing disorder. It is well known that stuttering has been described as a speech motor disorder that interrupts the timing and/or coordination between the respiratory, laryngeal, and vocal tract subsystems of speech. ${ }^{1-6}$ However, other authors have described the cognitive, linguistic, and psycholinguistic components of the disorder that can influence a person's overall communicative competence. ${ }^{7,8}$ The pervasive nature of stuttering defies a uniform definition, however, because stuttering includes core surface speech elements, such as repetitions, prolongations, and cessations of sounds interwoven with elements that exist below the surface. Such covert or affective components include stress, anxiety, and negative reactions to speaking in general. These layers of difficulty often manifest in significantly reduced quality of life for the person who lives with a stutter on a daily basis. ${ }^{9,10}$

Many clinical researchers have noted there is more to the stuttering disorder than just the surface features. ${ }^{10-19}$ Historically, Sheehan described stuttering using an "iceberg" analogy in which the speaker's experience of the stuttering disorder is represented as the region "under the surface." 15 The nature of stuttering has the potential to elicit ridicule, embarrassment, frustration, and/or pity from the listener; therefore, it is inevitable that it is associated with some degree of fear, anxiety, and/or frustration in the person who stutters. ${ }^{20-23}$ Researchers and clinicians have argued for a more expansive model of stuttering, which presents not only the surface behaviors in an individual's speech but also the psychosocial impact or consequences stuttering has on their life. ${ }^{19,24-28}$

This concept of looking at stuttering from a layered perspective appealed to the group of clinicians who work in the largest stuttering treatment clinic in Western Australia-the Curtin Stuttering Treatment Clinic at Curtin University in Perth. This is a specialized community-based clinic established for over 30 years as a student training facility. It embraces the life span of stuttering, treating toddlers through senior citizens. Since inception, the clinic has treated over 8,000 clients and presently there are three concurrent clinics managing over 50 clients per week.

Clients and their family are involved in individualized therapy tailored to their specific fluency needs. In addition to individual treatment sessions, groups for school-aged children, adolescents, and adults are run in afternoon and evening sessions with holistic psychosocial and fluency objectives underpinning each group. The parents, siblings, and partners accompany the person to their treatments at various times, and there are support groups conducted for these family members as well.

The specialized nature of the clinic means that often clients with concomitant difficulties or complex, long-standing communication needs are referred on by other clinicians. Given the diverse range and complexity of the fluency difficulties with which we work, the concept and necessity of seeing beyond the stutter and managing more of the psychosocial issues evolved naturally for all of us working in the clinic. We undertook research that had a direct bearing on the clinical initiatives we were 
incorporating into our daily practice, and this involved two primary fundamental principles:

1. If we are going to claim to support all aspects of a stuttering disorder, a holistic therapeutic model to treat stuttering is necessary. There needs to be a designated benefit in assimilating fluency techniques at the same time as the psychosocial impact and consequences of stuttering are managed.

2. If we are going to administer truly efficacious therapy, we also need to address the influence that stuttering has not only on the individuals but on their family members as well. The most important emotional unit to which we belong, and the one that affects the course and outcome of our lives the most, is our family. Recent clinical research has shown that it is imperative to understand how the impact of a disorder, and responsibility for its treatment, is distributed among the entire family unit and all the members therein.

As our esteemed colleague Willie Botterill from the Michael Palin Centre wrote before she retired, no single component of the family can be understood in isolation from the others. Ultimately, the whole family, not just the isolated individual with the disorder, is described as the most accurate and correct definition of "client." 29

\section{THE IMPACT OF STUTTERING ON SCHOOL-AGED CHILDREN AND ADOLESCENTS}

To begin, we wanted to gain deeper insight regarding the effects living with a stutter has on our school-aged children and adolescents alike. Parental reports have indicated that children who stutter are aware of their stuttering shortly after its onset, and thus social interaction can be impaired from an early age. ${ }^{30,31}$ Children who stutter have been found to experience more negative attitudes toward speech than those who are normally fluent, even as young as 3 and 4 years of age, and these negative attitudes appear to worsen with age and stuttering severity. ${ }^{32-37}$
To date, research has not delineated the nature or extent of the negative impact that stuttered speech has on the vulnerable schoolaged and adolescent age groups. This age bracket has been described in health research as "invisible" as these children and teens are significantly at risk for mental health problems. Themes that have emerged in qualitative mental health research with such young people include those of secrecy, not wanting to talk to adults, very strong emotional feelings, and the conflicting need and desire for time to themselves or with other young people, but not with parents, teachers, or counsellors. $^{38}$

Thus, we wanted to know the ways in which negative experiences toward speaking affect school-aged children and adolescents and in terms of trajectory when these reactions emerge developmentally. In addition, we wanted to know if these experiences were unique to young people who stutter. These ages represent times of change in young people's lives, and it is not necessarily clear which aspects of the experience of stuttering are unique to stuttering and which are perhaps just part of growing up and learning to communicate with others. We chose to examine in detail the reactions and experiences of children and adolescents $(n=95)$ who stutter, directly comparing them to a matched control group of young people who do not stutter $(n=95){ }^{39}$ The findings are more fully explored in two articles that I have written with my clinical research team. ${ }^{38,39}$

What we know about the experiences of young people who stutter, and why this is important in their treatment:

- These young people experience a reduced quality of life compared with their fluent peers.

- These young people are hurting because of their speech difficulties-particularly the adolescents.

- They experience greater adverse impact on their lives than do their fluent peers-particularly in their social interactions.

- They have greater concerns about speaking and magnified affective, behavioral, and 
cognitive reactions to speaking and significantly compromised communication in daily situations.

- There is a significant association between stuttered speech frequency and self-awareness and knowledge of their stuttering experience (as measured by the Overall Assessment of Speakers' Experience of Stuttering-Standard Interview ${ }^{40}$ ) for children.

- But, interestingly, there is no significant correlation between stuttered speech frequency and other sections of the Overall Assessment of Speakers' Experience of Stuttering-Standard Interview for adolescents. That is, as the child gets older, adverse impact is not determined by overt speech disruptions. ${ }^{38,41,42}$

- The traditional surface severity of the young person's stuttered speech does not indicate how much they may be struggling with the impact of the disorder. The surface picture is potentially misleading-those who present as "mild" may well be suffering as much or more than those whose stuttered speech is more noticeable and visible.

- An important clinical implication emerged from the finding that young people who were fluent also had some degree of negative reaction to their speaking ability. Many people have unfavorable impressions of their speaking ability. Thus, the goal of therapy addressing negative reactions to stuttering does not necessarily need to seek an outcome of "zero negative reactions" to be successful. Helping a child achieve "normal" reactions (which may include some low level of concern about speaking) may be a more reasonable outcome.

- Finally, inclusion of strategies for managing the psychosocial impact of stuttering as well as the stutter per se in a holistic approach to the treatment of young people who stutter appears to be imperative in setting up therapy goals. Clinical assessment regarding young peoples' attitudes toward their communication is a priority and psychosocial support to reduce anxiety levels and negative expectancies are equally important as strategies for fluent speech.

\section{THE IMPACT OF STUTTERING ON SIBLINGS}

It was evident in the families who attend the Curtin Stuttering Treatment Clinic that within the family constellation, the closest person to the individual who stutters is often their sibling. It has been suggested that the emotional ties between siblings are second only to those between children and their parents and that these sibling relationships are unique in terms of their power and vitality in the child's wellbeing and development. ${ }^{43}$ Despite these findings, the impact of stuttering and stuttering therapy on the siblings of a child who stutters and the subsequent quality of the sibling relationship had previously not been thoroughly explored.

It has been suggested by Bank and Kahn that siblings follow a particular relationship life cycle. ${ }^{44}$ In early childhood, they provide a constant source of companionship; during the school years, they extend themselves to others external to the family; and during adolescence, siblings demonstrate ambivalence regarding their relationship but still confide in and advise each other to a considerable extent. ${ }^{45}$ Siblings, in general, share the majority of time with each other, especially during childhood, and often greater time with each other than with their parents. $^{46}$

Barr and colleagues explored the experiences and impact that a speech impairment had on siblings in the context of a family-centered practice therapy. ${ }^{47}$ When others were present, the sibling tended to interpret and speak for the child with the speech impairment to protect them from being misunderstood and potentially embarrassed. Siblings described personal difficulties, including jealousy and concern about their sibling with the speech impairment. Positive features, however, were also described by these siblings, including such attributes as increased maturity and insight, tolerance, pride, advocacy, loyalty, strength, and resilience. ${ }^{48}$

Thus, we were interested to know siblings' perspectives on the impact of stuttering on their sibling, on their parents, and on themselves. In addition, we wanted to know their views on the therapy being administered. In our 2012 study, ${ }^{49}$ we enlisted $(n=12)$ sibling dyads and their parents where one child in the dyad 
stuttered plus matched control $(n=12)$ sibling dyads and their parents where both siblings were fluent, for a total of 96 participants.

What we found and the clinical implications for siblings of young people who stutter:

- Fluent siblings exhibited strong emotions regarding their sibling who stutters-both positive and negative. The emotions described by the fluent sibling appeared independent of the stuttering severity ratings of their siblings, with children with mild stuttering generating the same reactions as those with severe stuttered speech.

- Three-quarters of the siblings reported that they had discussed stuttering with their parents, but only one child explained that their feelings and impressions about stuttering had been sought. Thus, stuttering had not been discussed with the vast majority of the siblings. The discussions with parents focused on ways to help the child who stutters, but the fluent sibling's insights and potential difficulties were not addressed.

- Children who stutter and their siblings demonstrated significantly greater closeness, and concurrently, increased conflict and status disparity, than did the fluent sibling dyads.

- Parents also demonstrated significantly greater partiality toward their children who stutter. No consistent partiality was found in the families of fluent children.

- Fluent siblings reported being frustrated by the child who stutters, but also being upset when they were bullied or teased by others.

- Half of the siblings often served as protection for the child who stuttered and identified this as a positive role with the potential to educate others.

- Two-thirds of the fluent siblings were involved in the therapy as a natural by-product of sharing more conversational interactions with the stuttering child than any other family members. Again, this was described as a positive and constructive role.

- Some siblings attributed their importance in the therapy program to their perception that they were "looked up to" by the child who stutters.
- The majority of siblings reported a desire to be more involved in the therapy process than they currently were.

- Family-centered interventions are useful and effective, but such dependence on parents-as-clinicians may produce increased pressure in the home. ${ }^{47,50}$ This is particularly important given that parent stress levels have been found to be a strong predictor of sibling adjustment difficulties. ${ }^{50}$

- Awareness and education regarding the potential impact of stuttering on the sibling relationship is imperative in successful and positive therapy. A better understanding of the impact of stuttering on siblings may lead to a healthier integration of the entire family in the treatment process and even enhanced support from siblings in the clinical process.

\section{THE IMPACT OF STUTTERING ON PARENTS}

The most complex partnership of all is that of the child who stutters and their parents. In our team discussions regarding this area of research, an impression that emerged consistently was that there are parents who can definitely be identified early in the therapeutic process as having great positive potential to work with the child's stutter. On the other hand, there are those who undoubtedly bring challenges to this process as well. We wanted to understand more clearly the methods underpinning different parenting styles, so that we could better equip ourselves to work with different styles of parenting and to potentially modify our practices and procedures to accommodate these differences across families.

Previous research in stuttering disorders has emphasized facets of parent-child attachment such as communicative styles of the parent, their speech characteristics, their attitudes, and their knowledge of stuttering. But, knowledge of the impact of stuttering on parents has been limited by a lack of empirical investigation. As Yairi and Ambrose stated in 2005, the "continuous influence of stuttering... on the child's family has largely been overlooked by investigators." focused on what the parent can do to help their 
child rather than on the crisis created for the family by the child who stutters.

School-aged children between the ages of 6 and 12 years old have unique psychosocial, affective, and behavioral developmental patterns that set them aside from preschoolers and adolescents. They are bridged between the two. Moving toward adolescence, they show increasing independence from their $\mathrm{pa}-$ rents at the same time as an increasing dependence on their peers for social, emotional, and academic support. ${ }^{52}$ School-aged children also demonstrate preliminary notions about their sense of self and personal identity in a growing awareness of future socialization. Consequently, the disruptive nature of stuttering may hamper the way young people engage in and practice social discourse. ${ }^{53}$ The growing demands placed on the school-aged child for increasing adultlike social competence can exacerbate communication anxiety. ${ }^{54}$

Therefore, the quality of the parent-child relationship plays an increasingly important role in providing the child with models of social competence, coping strategies, and motivation in life.

Evidence from psychology and psychiatry has suggested that optimal parenting equips children with effective social adjustment and coping resilience. ${ }^{55-57}$ Securely attached children are more enthusiastic and have better problem-solving skills than others without the same degree of attachment with their parents. $^{58}$

Our study aimed to examine whether measures of parenting styles, parent and peer attachment patterns, and parent- and self-reported child behavior could differentiate school-aged children who stuttered from their fluent peers. ${ }^{59}$ In the light of such previous findings in other disciplines, the question revolved around whether distinctive parenting styles and resultant unique parent-child attachment patterns existed for a population of school-aged children and their parents compared with their fluent peers and their parents. The goal was not to look for blame or responsibility in the parent-child relationships, but rather to explore the impact that stuttering has on important family processes. From our clinical waiting list for treatment, school-aged chil- dren who stutter $(n=10)$ and their parents $(n=20)$ were compared with matched control normally fluent $(n=10)$ children and their parents $(n=20) .^{59}$

- In terms of parenting styles, there were no significant differences found between the parents of children who stutter and the parents of normally fluent children. The separate evaluation of particular parenting styles of mothers and fathers also yielded no statistically significant results.

- Parents of children who stutter rated these children as showing significantly more behavior difficulties than their normally fluent children.

- Children who stutter rated their parents with significantly lower parental attachment than fluent children did for their parents.

- Children who stutter perceived their parents with significantly lower parental trust than did their fluent peers. Such findings are consistent with the possibility that the continued experience with stuttering over time impacts on the quality of the relationship between a parent and their child.

- The majority of children who stutter reported frustration with the manner in which their parents attempted to manage their stuttering episodes.

- Young people who stutter reported frustration not only with the ways their parents attempted to shape their fluency but also with how the parents disclosed information regarding their stuttering. There was general consensus that the child would have preferred more autonomy in these decisionmaking processes.

- The majority of children who stutter reported that their friends were aware of the stutter, but were not unduly concerned by it. They also reported friends who helped them with their speech, and appreciation of these attempts to help manage their fluency. This is in contrast to the aggravation these same children expressed when reflecting on their parents' management attempts.

- The results demonstrated the serious consequences of stuttering intruding on and 
interfering with natural family communication.

- It is likely that the chronic nature of stuttering over time may impact on or alter parenting styles. Parents of children who stutter have to work harder to engage their children and compensate for their difficulties than do parents of normally fluent children.

- The finding that children who stutter perceive their parents with significantly lower attachment than their fluent counterparts highlights the importance of clinical management for these families to include the nature and quality of the interactions between the parent and their child. ${ }^{60}$ Given the pervasive influence that parents have on their children, educating them to recognize the potential impact their actions can have on the child is a crucial and enormously satisfying aspect of the therapeutic process.

- The collective findings from this study highlight a need to address a broader conceptualization of stuttering. The complexities of the stuttering disorder and its impact on life relationships were reported by every participant and their parents alike. For clinicians, there is a need to be cognizant of the psychosocial impact of the stutter on the entire family constellation.

- Because each family dynamic is unique, there is no "one size fits all" in the management of childhood stuttering; clinicians will need to individually assess and then problem solve the unique and complex relationship issues among their children who stutter, their parents, and their siblings.

\section{THE IMPACT OF STUTTERING ON PARTNERS}

The adult stuttering treatment we undertake evolved from a family system's philosophy in that the partner is typically involved in the therapy process. Because of this viewpoint and the large numbers of adults with whom we work, the priority emerged for us to gain a greater appreciation and understanding of the experiences of these partners. In looking at the research to date, it has explored others' percep- tions of the person who stutters from the point of view of teachers, professionals, employers, and peers. However, there is limited information regarding the impact on the most intimate relationship of all-that between the adult who stutters and their life partner.

Adults often view their stutter as an obstacle to developing relationships with potential partners. ${ }^{61,62}$ Hallmark research was conducted in the 1990s by the Bobergs through their investigation of the "other side of the block" from the spouse's perspective. ${ }^{63}$ Furthermore, Julia Boberg and Deborah Kully raised awareness regarding the pivotal role that the spouse could play in fluency therapy. ${ }^{64}$ Other research has recognized that supportive relationships serve as a critical element beneficial to the overall experience of therapy. ${ }^{65}$ Still, specific issues related to how a stuttering disorder might affect the quality of life of fluent partners, or how the presence of a fluent partner might affect an individual who stutters, have yet to be examined. We were interested in exploring the nature of the role of the fluent partner and the range of their personal experiences that are relatively unexplored in a study that we recently completed. ${ }^{66}$ Participants $(n=20)$ included working couples in their twenties through to retirees in their sixties. There was a cross section of couples; some with children, some without, and some who were grandparents. ${ }^{66}$

What we found and the clinical implications for both partners and adults who stutter:

- Key findings from our research with partners included that facts that people who stutter and their fluent partners reported similar knowledge of stuttering, similar personal reactions to stuttering, and a similar degree to which stuttering affects communication. There was great congruence in their responses, in that they viewed stuttering in the same way.

- Qualitative results indicated that the participants shared life experiences regarding reactions to stuttering. Strong emotive issues were raised by personal accounts from both partners. There were similar significant concerns expressed with social interactions and anxiety. Nearly half of the partners expressed feelings 
of overprotection toward their loved ones and anguish as they watched them speak.

- The fluent partners reflected on and explained the support that they felt they provided to their stuttering spouse on a regular basis. This type of support varied from explicit provision of a target word during moments of disfluency in conversation to broader concepts of patience in allowing the person who stutters to express themselves without pressure. Further, most fluent spouses encouraged their spouse to seek therapy and described the support they provided regarding the range of decisions their partner made in the pursuit of fluency.

- Participants referred to the notion of "acceptance" of the stutter without regarding it as a limitation in their relationship.

- Honesty and integrity were articulated as important relationship components on a consistent basis.

- However, no relationship was seen between the two groups (stuttering spouse and fluent partner) in terms of perceived impact on quality of life. This implies that partners may still not be fully aware of the true extent of the adverse impact that stuttering has on their loved one's overall quality of life.

- Spouses' comments also highlighted the intricate and complex changes that therapy can bring about.

- Across disciplines, the literature indicates that a positive treatment outcome for an individual is directly related to the family's commitment to and involvement in the treatment process. Luterman demonstrated in 1996 that if you "take good care of the spouse, the identified patient will also do well." ${ }^{67}$ The findings from our research seem to support Carlisle's suggestion that many adults who stutter are indeed fortunate in their choice of life partner. ${ }^{68}$

- We believe that the potential for partners to be agents of change to augment our treatments is powerful and undeniable and that more successful therapy results from encouragement and involvement of the spouse.

- Our findings provide support for a broadbased clinical program for adults who stutter that includes the fluent partner as a support in their treatment efforts. Over their lifetime, the partner usually spends more time with this person than anyone else. It makes sense that they are a logical and valuable resource. A more complete understanding of the therapy process is achieved by involving the spouse from the outset.

\section{KNOWING ABOUT THE PSYCHOSOCIAL IMPACT IS NOT ENOUGH}

We have described the affective, behavioral, and cognitive impacts of stuttering, in addition to the adverse effect on overall quality of life, which arise from living with a stuttering disorder. In our work, it is clear that stuttering has an impact on relationships within the family, in particular for the sibling, the parent, and the partner of the person who stutters. However, the relationship between speech fluency and these impacts is not transparent: The traditional surface severity of stuttered speech does not indicate how much the person may be struggling with the impact of the disorder. Clinical assessment regarding the person's attitude toward their communication is a priority, and psychosocial support to reduce anxiety levels and negative expectancies is equally important as the actual strategies for fluent speech.

Further clinical insights arose with each population studied. For example, the schoolaged children who stuttered reported frustration with the nature in which their parents tried to manage their stuttered speech. In addition, they wanted to be present when their stutter was explained to their teachers. Such seemingly minor yet important practical considerations endorse future family-based interventions.

The research presented in this article has highlighted the need and value for stuttering treatments to include a psychosocial management component. The demonstrated impacts that stuttering evokes, provide the groundwork for treatments that support psychological flexibility. Consequently, research conducted in the Curtin Stuttering Treatment Clinic has recently investigated the effectiveness of a novel integrated Acceptance and Commitment Therapy (ACT) program for adults who stutter. ${ }^{69,70}$ 
In addition, the motivation for this effectiveness-based study was clinical in nature. The Curtin Stuttering Treatment Clinic is a center offering specialized clinical expertise and is respected as a second opinion clinic for previously unsuccessful stuttering treatments. Each adult had formerly been provided with speech pathology therapy intervention, but it had been deemed not to have achieved significant improvement or success.

Previous adult treatment outcome studies have documented the use of cognitive behavioral therapy (CBT) for adults who stutter. ${ }^{71-73}$ Such CBT treatment components specifically target increasing optimistic attitude and decreasing negative cognitive appraisal through direct attempts to change maladaptive attitudes toward communication and social anxieties. The literature, however, indicates that efforts to repress undesired thoughts may be unworkable and even counterproductive. Efforts to eradicate unwanted thoughts seem to highlight and reinforce them further, which results in increases in unwanted thoughts especially in times of stress. ${ }^{74-76}$ Considering the chronic environmental stressors in the life of a person who stutters, we thought it appropriate to explore a different approach to the management of experiential avoidance through a treatment model that encourages psychological flexibility instead of control. The six core processes that contribute to psychological flexibility in the ACT model are self-concept, defusion, acceptance, mindfulness, values, and committed action. ${ }^{69,77} \mathrm{ACT}$ as a treatment option has been shown to expand behavioral choices, reduce emotional reactivity, and improve quality of life for individuals having chronic medical and psychological issues in other disorders. ${ }^{78-80}$ To date, however, no research had investigated how the core processes of an integrated ACT model could help adults who stutter deal with the impact of the disorder more effectively.

The integrated ACT program that we wrote focused on effective communication techniques for improving frequency of stuttering at the same time as strategies addressing psychosocial functioning, readiness for therapy and change, utilization of mindfulness skills, and psychological flexibility for adults who stutter. $^{69,70}$ The results for the 20 adults who stutter (10 men and 10 women) showed that all participants experienced significant reductions in the adverse impact of stuttering on their lives, an increase in their readiness for change, an improvement in their mindfulness skills, and a reduction in their overall frequency of stuttering. ${ }^{70}$ Furthermore, these psychosocial and fluency gains were maintained for a 3-month period after the treatment ceased. ${ }^{70}$

The program helped people who stutter focus on their personal values through a flexible treatment paradigm that incorporated both speech changes and psychosocial changes in an ACT framework. It led to consistent, positive changes for a wide range of individuals who stutter. ${ }^{70}$ The results showed us how the impact of stuttering on the speaker and others in their environment has the potential to be managed through a novel and beneficial integrated treatment philosophy.

\section{REFERENCES}

1. Caruso A, Max L, McClowry M. Perspectives on stuttering as a motor speech disorder. In: Caruso A, Strand E, eds. Clinical Management of Motor Speech Disorders in Children. New York, NY: Thieme; 1999:319-325

2. Kent RD. Research on speech motor control and its disorders: a review and prospective. J Commun Disord 2000;33(5):391-427, quiz 428

3. Nudelman HB, Herbrich KE, Hess KR, Hoyt BD, Rosenfield DB. A model of the phonatory response time of stutterers and fluent speakers to frequencymodulated tones. J Acoust Soc Am 1992;92(4 Pt 1): 1882-1888

4. Peters HF, Hulstijn W, Van Lieshout PH. Recent developments in speech motor research into stuttering. Folia Phoniatr Logop 2000;52(1-3): 103-119

5. Peters HFM, Starkweather CW. The interaction between speech motor coordination and language processes in the development of stuttering: hypotheses and suggestions for research. J Fluency Disord 1990;15(2):115-125

6. van Lieshout P, Hulstijn W, Peters H. Searching for the weak link in the speech production chain of people who stutter: a motor skill approach. In: Maasan B, van Lieshout P, Hulstijn W, Peters H, eds. Speech Motor Control in Normal and Disordered Speech. Oxford, England: Oxford University Press; 2004:313-355

7. Healey EC, Scott-Trautman L, Susca M. Clinical applications of a multidisciplinary approach for the 
assessment and treatment of stuttering. Contemp Issues Commun Sci Disord 2004;31:40-48

8. Wall M, Myers F. Clinical Management of Childhood Stuttering. Baltimore, MD: University Park Press; 1984

9. Blomgren M. Stuttering treatment for adults: an update on contemporary approaches. Semin Speech Lang 2010;31(4):272-282

10. Manning WH. Clinical Decision Making in Fluency Disorders. 3rd ed. Clifton Park, NY: Delmar, Cengage Learning; 2010

11. Cooper EB. Chronic perseverative stuttering syndrome: a harmful or helpful construct? Am J Speech Lang Pathol 1993;2:11-15

12. Manning WH. Progress under the surface and over time. In: Bernstein Ratner N, Healey C, eds. Stuttering Research and Practice: Bridging the Gap. Mahwah, NJ: Lawrence Earlbaum, Inc.; 1999:123-130

13. Murphy WP. A preliminary look at shame, guilt, and stuttering. In: Bernstein-Ratner N, Healey EC, eds. Stuttering Research and Practice: Bridging the Gap. Mahwah, NJ: Lawrence Earlbaum Inc.; 1999:131-143

14. Shapiro D. Stuttering Intervention: A Collaborative Journey to Fluency Freedom. Austin, TX: ProEd; 1999

15. Sheehan JG. Stuttering: Research and . New York, NY: Harper \& Row; 1970

16. Starkweather CW, Givens-Ackerman J. Stuttering. Austin, TX: Pro-Ed; 1997

17. Van Riper C. The Nature of Stuttering. Englewood Cliffs, NJ: Prentice-Hall; 1982

18. Yaruss JS. Describing the consequences of disorders: stuttering and the international classification of impairments, disabilities, and handicaps. J Speech Lang Hear Res 1998;41(2):249-257

19. Yaruss JS, Quesal RW. Stuttering and the international classification of functioning, disability, and health: an update. J Commun Disord 2004;37(1): 35-52

20. Bloodstein O, Bernstein Ratner N. A Handbook on Stuttering. 6th ed. Clifton Park, NY: Thomson Delmar Learning; 2008

21. Lincoln M, Onslow M, Menzies R. Beliefs about stuttering and anxiety: research and implications. Australian Journal of Human Communication Disorders 1996;24:3-10

22. Menzies R, Onslow M, Packman A. Anxiety and stuttering: exploring a complex relationship. Am J Speech Lang Pathol 1999;8(1):3-10

23. Reitzes P. Providing mentors, role models, and peer support for children who stutter. J Stutt Ther . Advocacy Res 2006;1:16-28

24. Cooper EB, Cooper CS. Clinician attitudes towards stuttering: two decades of change. J Fluency Disord 1996;21(2):119-135
25. Gabel RM. Effects of stuttering severity and therapy involvement on attitudes towards people who stutter. J Fluency Disord 2006;31(3):216-227

26. Quesal RW. Stuttering research: have we forgotten the stutterer? J Fluency Disord 1989;14(3): 153-164

27. Rustin L, Cook F, Spence R. The Management of Stuttering in Adolescence: A Communication Skills Approach. London, UK: Whurr Publishers; 1995

28. Yaruss JS, Quesal RW. Overall Assessment of the Speaker's Experience of Stuttering (OASES): documenting multiple outcomes in stuttering treatment. J Fluency Disord 2006;31(2):90-115

29. Botterill W. Developing the therapeutic relationship: from "expert" professional to "expert" person who stutters. J Fluency Disord 2011;36(3):158-173

30. Ambrose NG, Yairi E. The development of awareness of stuttering in preschool children. J Fluency Disord 1994;19(4):229-245

31. Packman A, Onslow M, Attanasio J. The timing of early intervention in the Lidcombe Program. In: Onslow M, Packman A, Harrison E, eds. The Lidcombe Program of Early Stuttering Intervention. Austin, TX: Pro-Ed; 2003:41-55

32. De Nil LF, Brutten G. Speech-associated attitudes, stuttering, voice disordered, articulation disordered, and normal speaking children. J Fluency Disord 1990;15(2):127-134

33. De Nil LF, Brutten GJ. Speech-associated attitudes of stuttering and nonstuttering children. J Speech Hear Res 1991;34(1):60-66

34. Vanryckeghem M. The communication attitude test: a concordancy investigation of stuttering and nonstuttering children and their parents. J Fluency Disord 1995;20:191-203

35. Vanryckeghem M, Brutten GJ. The speech-associated attitude of children who do and do not stutter and the differential effect of age. Am J Speech Lang Pathol 1997;6(4):67-73

36. Vanryckeghem M, Brutten GJ, Hernandez LM. A comparative investigation of the speech-associated attitude of preschool and kindergarten children who do and do not stutter. J Fluency Disord 2005;30(4):307-318

37. Vanryckeghem M, Hylebos C, Brutten GJ, Peleman $\mathrm{M}$. The relationship between mal-attitude and negative emotion among children who stutter. J Fluency Disord 2001;26(1):1-15

38. Mulcahy K, Hennessey N, Beilby J, Byrnes M. Social anxiety and the severity and typography of stuttering in adolescents. J Fluency Disord 2008; 33(4):306-319

39. Beilby JM, Byrnes ML, Yaruss JS. The impact of a stuttering disorder on Western Australian children and adolescents. Perspectives on Fluency and Fluency Disorders 2012;22(2):51-62 
40. Yaruss JS, Quesal RW, Coleman C. Overall Assessment of the Speakers' Experience of Stuttering-Standard Interview. San Antonio, TX: Pearson; 2010

41. Blumgart E, Tran Y, Yaruss JS, Craig A. Australian normative data for the Overall Assessment of the Speaker's Experience of Stuttering. J Fluency Disord 2012;37(2):83-90

42. Koedoot C, Versteegh M, Yaruss JS. Psychometric evaluation of the Dutch translation of the overall assessment of the speaker's experience of stuttering for adults (OASES-A-D). J Fluency Disord 2011; 36(3):222-230

43. Furman W, Buhrmester D. Children's perceptions of the qualities of sibling relationships. Child Dev 1985;56(2):448-461

44. Bank SP, Kahn MD. The Sibling Bond. New York, NY: Basil Books Inc.; 1982

45. Seligman M, Darling R. Ordinary Families: Special Children. 2nd ed. New York, NY: The Guilford Press; 1997

46. Dodd LW. Supporting the siblings of young children with disabilities. Br J Spec Educ 2004; 31(1):41-49

47. Barr J, McLeod S, Daniel G. Siblings of children with speech impairment: cavalry on the hill. Lang Speech Hear Serv Sch 2008;39(1):21-32

48. Russell C, Russell C, Russell M. We're here too: supporting "sibs" of children with special needs. Except Parent 2003;33:36-39

49. Beilby JM, Byrnes ML, Young KN. The experiences of living with a sibling who stutters: a preliminary study. J Fluency Disord 2012;37(2): 135-148

50. Pratt C, Botting N, Conti-Ramsden G. The characteristics and concerns of mothers of adolescents with a history of SLI. Child Lang Teach Ther 2006;22(2):177-196

51. Yairi E, Ambrose N. Early Childhood Stuttering. Austin, TX: Pro-Ed; 2005

52. Conture EG, Guitar B. Evaluating efficacy of treatment of stuttering: school-age children. J Fluency Disord 1993;18(2-3):253-287

53. La Greca AM, Lopez N. Social anxiety among adolescents: linkages with peer relations and friendships. J Abnorm Child Psychol 1998;26(2):83-94

54. Bukatko D, Daehler MW. Child Development: A Thematic Approach. 5th ed. Boston, MA: Houghton Mifflin; 2004

55. Engels RCME, Finkenauer C, Deković M, Meeus W. Parental attachment and adolescents' emotional adjustment: the associations with social skills and relational competence. J Couns Psychol 2001; 48(4):428-439

56. Hoeksma JB, Oosterlaan J, Schipper EM. Emotion regulation and the dynamics of feelings: a conceptual and methodological framework. Child Dev 2004;75(2):354-360
57. Padilla-Walker LM. Characteristics of motherchild interactions related to adolescents' positive values and behaviors. J Marriage Fam 2007;69(3): 675-686

58. Ainsworth MDS. Infant-mother attachment. Am Psychol 1979;34(10):932-937

59. Lau SR, Beilby JM, Byrnes ML, Hennessey NW. Parenting styles and attachment in school-aged children who stutter. J Commun Disord 2012; 45(2):98-110

60. Millard SK, Nicholas A, Cook FM. Is parent-child interaction therapy effective in reducing stuttering? J Speech Lang Hear Res 2008;51(3): 636-650

61. Hayhow R, Cray AM, Enderby P. Stammering and therapy views of people who stammer. J Fluency Disord 2002;27(1):1-16, quiz 16-17

62. Van Borsel J, Brepoels M, De Coene J. Stuttering, attractiveness and romantic relationships: the perception of adolescents and young adults. J Fluency Disord 2011;36(1):41-50

63. Boberg JM, Boberg E. The other side of the block: the stutterer's spouse. J Fluency Disord 1990;15(1): 61-75

64. Boberg E, Kully D. Comprehensive Stuttering Program. San Diego, CA: College-Hill Press; 1985

65. Corcoran JA, Stewart M. Stories of stuttering: a qualitative analysis of interview narratives. J Fluency Disord 1998;23(4):247-264

66. Beilby JM, Byrnes ML, Meagher EL, Yaruss JS. The impact of stuttering on adults who stutter and their partners. J Fluency Disord 2013;38(1): $14-29$

67. Luterman D. Techniques of counseling. In: Luterman D, ed. Counseling Persons with Communication Disorders and Their Families. 3rd ed. Austin, TX: Pro-Ed; 1996

68. Carlisle JA. Tangled Tongue: Living with a Stutter. Toronto, Canada: University of Toronto Press; 1985

69. Beilby JM, Byrnes ML. Acceptance and Commitment Therapy for people who stutter. Perspect Fluen Fluen Disord 2012;22:34-46

70. Beilby JM, Byrnes ML, Yaruss JS. Acceptance and Commitment Therapy for adults who stutter: psychosocial adjustment and speech fluency. J Fluency Disord 2012;37(4):289-299

71. Andrews G, Craig A. Stuttering: overt and covert measurement of the speech of treated subjects. J Speech Hear Disord 1982;47(1):96-99

72. Andrews G, Feyer AM. Does behavior therapy still work when the experimenters depart? An analysis of a behavioral treatment program for stuttering. Behav Modif 1985;9(4):443-457

73. Craig A, Andrews G. The prediction and prevention of relapse in stuttering. The value of selfcontrol techniques and locus of control measures. Behav Modif 1985;9(4):427-442 
74. Wegner DM. Ironic processes of mental control. Psychol Rev 1994;101(1):34-52

75. Wenzlaff RM, Wegner DM, Roper DW. Depression and mental control: the resurgence of unwanted negative thoughts. J Pers Soc Psychol 1988; 55(6):882-892

76. Wenzlaff RM, Wegner DM. Thought suppression. Annu Rev Psychol 2000;51:59-91

77. Hayes SC, Strosahl K, Wilson KG. Acceptance and Commitment Therapy: An Experiential Approach to Behavior Change. New York, NY: Guildford Press; 1999
78. Donaldson-Fielder EJ, Bond FW. Psychological acceptance and emotional intelligence in relation to workplace well-being. Br J Guid Counc 2004; 32(2):187-203

79. McCracken LM, Vowles KE. Psychological flexibility and traditional pain management strategies in relation to patient functioning with chronic pain: an examination of a revised instrument. J Pain 2007;8(9):700-707

80. Sloan DM. Emotion regulation in action: emotional reactivity in experiential avoidance. Behav Res Ther 2004;42(11):1257-1270 